\title{
Effects of Liberalization on Domestic Product Quality
}

\author{
Tarun Kabiraj \\ Indian Statistical Institute, India \\ Soma Roy \\ Dum Dum Motijheel College,India
}

\begin{abstract}
In a model of vertical product differentiation we study the impact of liberalization on the choice of the product quality of a local monopolist. We show that under liberalization as one foreign firm enters with a superior quality, the local firm will reduce its quality level unless the foreign firm's product quality is sufficiently higher. As the efficiency of the local firm goes up, its quality choice responds more under liberalization than under protection. However, its market size in the protective regime is independent of its efficiency level.
\end{abstract}

- JEL classification: L11, O12

- Keywords: Product Quality, Competition, Efficiency, Protection, Liberalization

\section{Introduction}

Since the beginning of the 1990s there has been a dramatic shift of economic policies in the developing nations. These countries have switched from a policy of protective trade and restricted entry to free trade and economic liberalization. For instance, in a country like India there has been a significant reduction of import tariffs and other trade barriers. In the post reform India the peak tariff rates have been brought down to a maximum of 50\% from the level of 355\% during 1990-91 to 1998-99 (Kumar, 2000). While one may debate over the possible effect of

*Corresponding address: Tarun Kabiraj, Economic Research Unit, Indian Statistical Institute, 203 B.T. Road, Kolkata - 700108, India. Fax: (91)(33)25778893, E-mail: tarunkabiraj@hotmail.com (C)2006-Center for International Economics, Sejong Institution, All Rights Reserved. 
liberalization on the overall wellbeing of the country concerned, but it is reasonably believed that such a policy will create competition in the local market because of entry of foreign goods. ${ }^{1}$ The advocates of the liberalization policy argue that such a policy is healthy from the viewpoint of the local country because not only consumers benefit from lower product price and import of new goods not produced domestically, but the competitive forces lead to higher domestic research and development (R\&D). In particular, they say, the local firms respond by increasing their product quality so as to remain competitive in the market. ${ }^{2}$ Evidently, in the protective regime the local firms enjoyed monopolistic rents but the local product quality was much below the international standard (Bhagwati, 1993). As an illustration, consider the consumer durable goods industries in India such as two wheelers and passenger cars. Even though the local firms enjoyed a large domestic market, they did not generate significant brand loyalty that could be used against the new entrants in the post reform period (Patibandla, 2002).

Then the important question is : Will a policy of economic liberalization lead to a higher domestic product quality? The purpose of the present paper is to study the effect of liberalization on the choice of the product quality by a local monopoly in the presence of entry of a foreign firm when liberalization takes place. Our paper shows that this depends on what product quality the foreign firm brings in. In particular, if the foreign firm enters with a product quality not high enough relative to the initial domestic quality, the local quality in equilibrium will fall. That the quality level of the product produced by local firms has declined after liberalization is evident from the work of Dholakia and Kapur (2001). The policy reforms have pushed the non-exporting firms to concentrate on the lower end of the domestic market. In case of refrigerator, for example, the empirical data supports that the transnational firms have been able to increase their demand by selling higher quality products at a higher price than local firms. Local firms cater to the lower

\footnotetext{
${ }^{1}$ With higher quality the MNCs capture the upper end of the market and the market share of local firms gets declined. For example, in the two wheeler industry the market share of Bajaj stood at $80 \%$ in the mid 80 's, have declined to $45 \%$ as the new entrants like Honda, Suzuki penetrated the domestic market. Similarly in the passenger car industry, though Maruti-Suzuki enjoys a major share of the market owing to its strong distribution network, the new entrants like Daewoo, Hyundai and Ford have been able to cut into its market share in recent years.

${ }^{2}$ Among others, Chandra and Sastry (1998) support the view that the competitiveness of the Indian corporate sector has increased in the post liberalization era. Indian firms seem to perceive quality as one key variable both for internal competition and export of the products. In their study consumers' perception of quality has increased by $21.7 \%$ during 1997 in the manufacturing sector.
} 
segment of the growing market coming from the middle income group.

In this paper we consider the following scenario. Initially there is monopoly of a local firm that supplies a product quality in the home market. Then a liberalization policy is implemented by removing all import tariff restrictions, and a foreign firm enters the same market with a higher quality of the product. Thus the market structure becomes a vertically differentiated duopoly consisting of a high quality foreign firm and a domestic firm producing a low quality of the same product. Obviously, the foreign firm captures the upper end of the market. We construct a two-stage game. In the first stage, given the foreign firm's quality, the local firm chooses its quality level; then in the second stage they simultaneously choose the price levels of their respective products. We assume that the domestic firm has a cost advantage in a sense that it can produce the same quality product at a lower cost than the foreign firm. This is possible because of the availability of the highly skilled manpower at a relatively lower cost in the domestic economy. The other possible reasons are accumulated learning, economies of production, the access to the rapidly improving communication network and other infrastructural facilities and the increase in R\&D activity. Some study (e.g., Dholakia and Kapur, 2001) supports that the ratio of R\&D to net sales has considerably increased after 1991. The cost advantage may be seen for many industrial goods for which the local firms already possessed superior technologies. One example is the computer software industry. Indian software developers offer a cost advantage of 40-60 percent over their American counterpart. This cost advantage in software industry is generated by its relative abundance of skilled software personnel, cost efficient maintenance of the existing mainframe systems and continuous development of new software for PCs, etc. The other factor may be that the local firms often have the country specific institutional knowledge and so have the advantage of a wellestablished distribution network. One example is Hindustan Lever Ltd., a reputed Indian company for detergents, soap, toothpaste, shampoo etc. It has a strong distribution network even in the extreme rural corner of India. This has generated a cost advantage to this company compared to its rivals. Theoretical support is also evident. The study by Balassa (1977) shows how with the passage of time the comparative advantage of the more advanced developing countries have declined in the products that require more cheap and unskilled labor.

There is a good amount of Industrial Organization literature that deals with the determination of product quality and prices. Gabszewicz and Thisse (1979) have shown that in the presence of differential qualities, consumers may go for just one 
quality product. Shaked and Sutton (1982) have investigated the choice of qualities by the firms and have provided the theory of maximum product differentiation. While Tirole (1988) considers the problem in a duopoly by assuming that firms cover the market, Choi and Shin (1992) have extended the analysis to the case when market is not fully covered. Wauthy (1996) have provided a complete characterization of quality choices in a duopoly model with vertical product differentiation. Finally, Motta (1993) has provided a model of vertical product differentiation to compare equilibrium qualities under price and quantity competition. The result depends on the assumption on costs, that is, whether the cost of quality is fixed or variable. However, Cournot competition gives rise to less product differentiation at equilibrium. ${ }^{3}$

Then this literature has been extended to study the impact of trade policy on product quality. This literature includes the works of Rodriguez (1979), Das and Donnenfeld (1987), and Krishna (1987), among others. ${ }^{4}$ These works, however, assume either a competitive industry or an industry in which the foreign firm has monopoly. Then Das and Donnenfeld (1989) have studied the problem in a duopoly. One of their results is that when the foreign firm produces the higher quality good, the imposition of a quota leads to higher quality of imports. The domestic firm responds by upgrading the quality of its product. Reitzes (1992) has also examined the quality choice in a duopoly with one foreign firm and one domestic firm. The paper shows that in the absence of set-up costs the domestic firm sets the socially optimal level of quality, but if set-up costs are present, its quality choice is below the socially optimal level unless there is a high level of protection.

The papers which have directly addressed to the problem of liberalization and its impact on product quality are by Tanaka (1995), Chatterjee and Raychaudhuri (2001) and Bose and Kemme (2002). Tanaka has a monopolistic framework. Consumers are located along a circle of unitary circumference. Firms compete with differentiated goods whose quality is endogenously determined. The numbers of local and foreign firms are fixed --- the foreign firms enter in the post-liberalization period. The paper shows that if the fixed cost for the firms is positive and increasing with respect to quality, trade liberalization lowers the quality of the

\footnotetext{
${ }^{3}$ Our model is similar to the model of Motta (1993) when there is price competition and the costs of quality are variable. However, in our model firms have different cost structures.

${ }^{4}$ Trade policy under incomplete information is also studied in the literature. See, for instance, Bagwell and Staiger (1989) and Donnenfeld (1986).
} 
products. The reason is that under liberalization the number of firms goes up and as a result the market segment for each firm shrinks, and the marginal profit with respect to quality decreases. The paper by Chatterjee and Raychaudhuri (2001) is more close to our present work. It studies the effect of removal of import tariffs on the product quality. The paper assumes that a foreign firm enters the local market after liberalization with a higher quality compared to that of the local monopolist, but the foreign firm is more cost efficient in production. The paper also assumes full market coverage. Then it is shown that the local firm in competition lowers its quality. In contrast, in our paper the market is not covered and the local firm is more efficient than the foreign firm. We show that local quality will be lower unless the foreign firm enters with a much superior quality. When the foreign firm enters with a sufficiently high quality, the local firm in competition improves its quality. This result has an obvious policy implication. An evaluation of the effect of a liberalization policy on the choice of the domestic quality depends on the consideration of what quality the foreign firm brings with it in the post liberalization period. The paper by Bose and Kemme (2002), on the other hand, studies the problem in the context of a transition economy when liberalization means lowering barriers of entry. While under liberalization local firms face lower entry costs, they will, however, have to spend an additional amount of money if to produce the high quality product. The paper shows that if the proportion of uninformed consumers is high, a liberalization policy will induce entry by low quality producers; hence the average quality of goods in the market falls.

Plan of the paper is the following. Section II provides the model. Under subheading A we describe the preference of the consumer for the vertically differentiated product and the cost functions of the foreign and the local firms. Subheadings B and C deal with 2.2 and 2.3 are devoted to the determination of equilibrium prices and quality of the product produced by the domestic firm under full protection and full liberalization, respectively. Then quality levels chosen by the domestic firm under two regimes are compared in Section III. Finally, concluding remarks are given in Section IV. All mathematical derivations are relegated to the appendix. 


\section{The Model}

\section{A. Description of the cost and preference structure}

\section{Preference Function:}

Let the utility function of a consumer with taste parameter $\alpha$ be

$$
U=\alpha u-P
$$

where $u$ is the quality of the product and $p$ is price. We assume that consumers are uniformly distributed over the interval and that each consumer can buy at most one unit of the product. Conveniently, we assume $\bar{\alpha}=1$. Thus a consumer with taste parameter $\alpha \in[0, \bar{\alpha}]$ will buy the product of quality $u$ at price $p$ as long as $U \geq 0$, that is,

$$
\alpha \cdot u . \geq p
$$

When there are two qualities available in the market, viz., $u_{i}$ and $u_{j}$, then we define that an $\alpha$ consumer will buy the product of quality $u_{j}$ at price $p_{j}$ instead of $u_{i}$ at price $p_{i}$ if and only if

$$
\alpha \cdot u_{j}-p_{j} \geq \alpha \cdot u_{i}-p_{i} \forall i \neq j
$$

\section{Cost Function:}

Consider a vertically differentiated good $X$. The quality of the good is observable to all and is indexed by a real number $u \in(0, \bar{u})$. The production technology of such a good is usually specified as:

$$
C(x, u)=c(u) x \text { with } c_{u}>0, c_{u u} \geq 0
$$

where $c(u)$ is the unit cost of producing one unit of $X$ of quality $u$. Thus production cost varies positively with quality improvement. Let the foreign firm's cost function with a given quality $u_{0}$ be

$$
C^{*}\left(u_{0}, x^{*}\right)=\frac{u_{0}^{2}}{2} x^{*}
$$


(superscript $*$ stands for foreign firm). The cost function for the domestic firm is

$$
C(u, x)=b \frac{u^{2}}{2} x
$$

where the parameter $b$ signifies the comparative efficiency of the domestic firm; $b<1$ means, the domestic firm is more efficient in developing the quality than the foreign firm; on the other hand, $b>1$ means the local firm is relatively inefficient. In our paper we restrict to the assumption that $b<1$.

\section{B. Domestic monopoly equilibrium}

Consider the scenario where the domestic firm is fully protected from foreign competition (say, by means of a tariff). We then determine the equilibrium quality $u_{m}$ and the price $p_{m}$ of the product to be charged by the local monopolist. The marginal consumer $\hat{\alpha}$ who is indifferent between buying or not buying the product is obtained from Eq. (1),

$$
\hat{\alpha}=\frac{p_{m}}{u_{m}}
$$

Therefore, for the given $u_{m}$ and $p_{m}$ the market demand for the local monopolist is

$$
x\left(u_{m}, p_{m}\right)=1-\alpha
$$

The monopolist chooses $u_{m}$ and $p_{m}$ to maximize his profit,

$$
\max _{u_{m}, p_{m}} \pi_{m}=\left(p_{m}-b \frac{u_{m}^{2}}{2}\right)\left(1-\frac{p_{m}}{u_{m}}\right)
$$

We have the following first order conditions:

$$
\begin{gathered}
\frac{\partial \pi_{m}}{\partial p_{m}}=\left(1-\frac{p_{m}}{u_{m}}\right)-\frac{1}{u_{m}}\left(p_{m}-\frac{u_{m}^{2}}{2}\right)=0 \\
\frac{\partial \pi_{m}}{\partial u_{m}}=-b u_{m}\left(1-\frac{p_{m}}{u_{m}}\right)+\frac{p_{m}}{u_{m}^{2}}\left(p_{m}-\frac{b u_{m}^{2}}{2}\right)=0
\end{gathered}
$$

Solving from (8) and (9) we shall get (see Appendix 1) 


$$
u_{m}=\frac{2}{3 b}, p_{m}=\frac{4}{9 b} \text { and } \pi_{m}=\frac{2}{27 b}
$$

One can easily check that second order and stability conditions are satisfied, that is,

$$
\frac{\partial^{2} \pi_{m}}{\partial p_{m}^{2}}<0, \frac{\partial^{2} \pi_{m}}{\partial u_{m}^{2}}<0 \text { and } \frac{\partial^{2} \pi_{m}}{\partial p_{m}^{2}} \cdot \frac{\partial^{2} \pi_{m}}{\partial u_{m}^{2}} .-\left(\frac{\partial^{2} \pi_{m}}{\partial u_{m} \partial p_{m}}\right)^{2}=\frac{3}{4} b^{2}>0
$$

Proposition 1: The higher the efficiency of the firm (i.e., lower b), the higher will be the equilibrium quality (i.e., higher $u_{m}$ ) and price $\left(p_{m}\right)$ of the product.

As firm's cost efficiency increases, its cost for developing a given quality decreases. It is obvious that in such a situation the firm will improve the quality level. Since consumers are willing to pay a higher price for the higher quality, the monopolist is successful to increase the price.

Proposition 2: Under protection the market size of the local monopolist is constant and independent of its efficiency level.

Proof: Using (10), the market size of the monopolist is $1-\hat{\alpha}=\frac{1}{3}$.

Under protection, the local monopolist maintains a fixed market size, but it can successfully increase its profit by increasing efficiency and so quality and price of the product. Note that in equilibrium the ratio of quality to price is independent of the efficiency level of the firm.

\section{Domestic quality under full liberalization}

Let us now consider the scenario where the local government has relaxed all tariff barriers. As a result entry of foreign firms into the domestic economy occurs. We assume that there is only one foreign firm to enter into the present industry and its quality of the product, $u_{0}$, is superior to the initial local monopoly quality, $u_{m}$. Thus given $u_{m}=\frac{2}{3 b}$ and the restriction that $b<1$ (see the previous section), our assumption regarding the parametric relationship is:

$$
\frac{2}{3 u_{o}}<b<1
$$

We further restrict to the assumption that $u_{0} \geq 1$. This also means that the interval of $b$ is non-empty. Then after liberalization when entry of a foreign firm 
occurs, the local firm will respond by choosing its quality level optimally. We assume that the local firm is not capable of improving its quality to the level of the foreign quality.

Thus in the post-liberalization situation we have now two firms in the industry. They play the following two-stage game. In the first stage, the local firm decides the quality of the product, $u$, on the assumption that $u<u_{o}$. This determines the marginal cost of producing the product, given the quality $u_{o}$ of the foreign firm. In the second stage, the firms simultaneously choose prices. We look for the sub-game perfect equilibrium of the game and this is obtained by backward induction method.

The marginal consumer, who is indifferent between buying quality $u_{o}$ or $u$, has the taste parameter $\alpha_{1}$ such that

$$
\alpha_{1} u_{o}-p_{1}=\alpha_{1} u-p_{2}
$$

where $p_{1}$ and $p_{2}$ are the prices charged by the foreign and local firms respectively. Therefore,

$$
\alpha_{1}=\frac{p_{1}-p_{2}}{u_{o}-u}
$$

Similarly, for the consumer who is indifferent between buying the local firm product and not buying at all has the taste parameter $\alpha_{2}=\frac{p_{2}}{u}$. Consumers for whom $\alpha_{1} \leq \alpha \leq 1$ will buy quality $u_{o}$ and the consumers for whom $\alpha_{2} \leq \alpha \leq \alpha_{1}$ will buy quality u. Quantity demanded for the foreign and local firm goods are respectively given by :

$$
x^{*}=1-\frac{p_{1}-p_{2}}{u_{o}-u} \text { and } x=\frac{p_{1}-p_{2}}{u_{o}-u}-\frac{p_{2}}{u}
$$

The corresponding profit functions are defined as

$$
\begin{gathered}
\pi_{1}=\left(p_{1}-\frac{u_{o}^{2}}{2}\right)\left(1-\frac{p_{1}-p_{2}}{u_{o}-u}\right) \\
\pi_{2}=\left(p_{2}-b \frac{u^{2}}{2}\right)\left(\frac{p_{1}-p_{2}}{u_{o}-u}-\frac{p_{2}}{u}\right)
\end{gathered}
$$

Second Stage

In the second stage the firms determine $p_{1}$ and $p_{2}$, taking $u_{o}$ and $u$ fixed. We 
have the following first order conditions for profit maximization:

$$
\begin{gathered}
\frac{\partial \pi_{1}}{\partial p_{1}}=\left(1-\frac{p_{1}-p_{2}}{u_{o}-u}\right)-\frac{1}{u_{o}-u}\left(p_{1}-\frac{u_{o}^{2}}{2}\right)=0 \\
\text { i.e., } 2 p_{1}-p_{2}=u_{o}-u+\frac{u_{o}^{2}}{2}
\end{gathered}
$$

and

$$
\begin{gathered}
\frac{\partial \pi_{2}}{\partial p_{2}}=\left(\frac{p_{1}-p_{2}}{u_{o}-u}-\frac{p_{2}}{u}\right)-\frac{u_{o}}{\left(u_{o}-u\right) u}\left(p_{2}-b \frac{u^{2}}{2}\right)=0 \\
\text { i.e., }-p_{1} u+2 u_{o} p_{2}=\frac{b u_{0} u^{2}}{2}
\end{gathered}
$$

Second order conditions can be easily checked, that is,

$$
\frac{\partial^{2} \pi_{1}}{\partial p_{1}^{2}}=-\frac{2}{u_{o}-u}<0, \frac{\partial^{2} \pi_{2}}{\partial p_{2}^{2}}=-\frac{2 u_{o}}{\left(u_{o}-u\right) u}<0
$$

and stability condition also holds, i.e.,

$$
\frac{\partial^{2} \pi_{1}}{\partial p_{1}^{2}} \frac{\partial^{2} \pi_{2}}{\partial p_{2}^{2}}-\left(\frac{\partial^{2} \pi_{1}}{\partial p_{1} \partial p_{2}}\right)^{2}=\left(\frac{1}{u o-u}\right) \frac{4 u_{o}-u}{u}>0
$$

Solving (13) and (14) simultaneously we get the following equilibrium prices as charged by the foreign and local firms,

$$
\begin{aligned}
& p_{1}=u_{o}\left[2\left(u_{o}-u\right)+u_{o}^{2}+b \frac{u^{2}}{2}\right] /\left(4 u_{o}-u\right) \\
& p_{2}=u\left[\left(u_{o}-u\right)+\frac{u_{o}^{2}}{2}+b u_{o} u\right] /\left(4 u_{o}-u\right)
\end{aligned}
$$

We have following results for the second stage subgame.

Lemma 1 : An increase of the local firm's quality necessarily increases the equilibrium price of the local firm, but whether foreign firm's price will go up or not depends on the extent of initial quality difference, that is, $\frac{\partial p_{2}}{\partial u}>0$ but $\frac{\partial p_{1}}{\partial u}>0$ when $u_{o}$ is relatively high. 
Proof: From first order conditions ((13) and (14)) and using second order and stability conditions we shall get

$$
\begin{aligned}
& \frac{\partial p_{1}}{\partial u}=\frac{1}{4 u_{o}-u}\left[-2 u_{0}+\left(b u_{o} u+p_{1}\right)\right] \\
& \frac{\partial p_{2}}{\partial u}=\frac{1}{4 u_{o}-u}\left[-u+2\left(b u_{o} u+p_{1}\right)\right] .
\end{aligned}
$$

Since $u_{m}<u_{o}$, therefore, $\frac{2}{3 b}<u_{o}$ or, $\frac{2}{3}<b u_{o}$. Hence,

$$
\frac{\partial p_{2}}{\partial u}>\frac{1}{4 u_{o}-u}\left(\frac{u}{3}+2 p_{1}\right)>0 \text {, }
$$

but,

$$
\frac{\partial p_{1}}{\partial u} \geq 0 \Leftrightarrow u_{o}^{2}-6 u_{o}+\frac{7}{3} u+\frac{b u}{2}\left(u_{o}-u\right) \stackrel{\geq}{<} 0 .
$$

Lemma 1 is rather intuitive. The higher the quality of the local firm's product, the higher will be its marginal cost of production, so higher will be the price. As the local firm charges a higher price for the better quality, the foreign firm will charge a lower price for the same quality in order to retain its market, if initial quality difference is not significant. On the other hand, if the initial quality difference is significantly high, the foreign firm will increase its price.

Lemma 2: An increase in local firm's quality increases both the upper end and the lower end of its market, i.e., $\frac{d \alpha_{1}}{d u}>0$ and $\frac{d \alpha_{2}}{d u}>0$.

Proof: Given $u_{o}$ and $u$, the upper end and the lower end of the local firm's market are defined as $\alpha_{1}=\frac{p_{1}-p_{2}}{u_{o}-u}$ and $\alpha_{2}=\frac{p_{2}}{u}$. Then it is proved in Appendix 2 that $\frac{d \alpha_{1}}{d u}>0$ and $\frac{d \alpha_{2}}{d u}>0$

This tells that by improving the quality the local firm can snatch a portion of the market from the foreign firm. The reason is that the consumer who is to consume the product of the foreign firm will now consume the local firm's product because it will enjoy more surplus from purchase of an inferior local product at a much lower price compared to the foreign product. On the other hand, the lower end of its market also goes up because with an increase in quality, the product price 
increases at a greater rate, given the production cost quadratic in quality.

\section{First Stage}

Now consider the quality choice by the local firm in the first stage whence the quality of the foreign firm is specified at $u_{0}$. The local firm chooses its quality to maximize its profit

$$
\pi_{2}=\left(P_{2}-b \frac{u^{2}}{2}\right)\left(\frac{p_{1}-p_{2}}{u_{o}-u}-\frac{p_{2}}{u}\right)
$$

The first order condition of this problem is

$$
\begin{aligned}
& \frac{\partial^{2} \pi_{2}}{\partial u}=\left(\frac{\partial p_{2}}{\partial u}-b u\right)\left(\frac{p_{1}-p_{2}}{u_{o}-u}-\frac{p_{2}}{u}\right)+ \\
& \left(p_{2}-b \frac{u^{2}}{2}\right)\left(\frac{p_{1}-p_{2}}{\left(u_{o}-u\right)^{2}}+\frac{1}{\left(u_{o}-u\right)} \frac{\partial p_{1}}{\partial u}-\frac{1}{\left(u_{o}-u\right)} \frac{\partial p_{2}}{\partial u}+\frac{p_{2}}{u^{2}}-\frac{1}{u} \frac{\partial p_{2}}{\partial u}\right)=0
\end{aligned}
$$

This can be reduced to (see Appendix 3)

$$
\begin{aligned}
& 2 b u^{4}-19 b u_{o} u^{3}+\left(38 b u_{o}+14-2 u_{o}\right) u_{o} u^{2}+\left(u_{o}-24 u_{o} b-22\right) u_{o}^{2} u \\
& +\left(8+4 u_{o}\right) u_{o}^{3}=0
\end{aligned}
$$

From this equation we can derive the equilibrium quality choice of the local firm, that is, $u\left(u_{0}, b\right)$. We consider simulation process to solve the values and characterize the results. Since Eq. (18) is a fourth degree polynomial, maximum four values may be obtained. After specifying the values of $b$ and $u_{0}$, we restrict to those values of $u$ which are real and lie within the range $0<u<u_{o}$ and for which the second order condition $\frac{\partial^{2} \pi_{2}}{\partial u^{2}}<0$ is satisfied. Since we have assumed $u_{m}<u_{0}$ and $b<1$, the permissible range of $\mathrm{b}$ (as specified earlier) is

$$
\frac{2}{3 u_{o}}<b<1 \text {. }
$$




\section{Results}

In this section we study the effect of liberalization on the choice of the domestic product quality. In particular we study whether the local product quality will go up when a foreign firm enters with a superior product. As liberalization occurs, the local firm now faces competition from its foreign counterpart. We show that this may lead to an improvement in the domestic product quality when the foreign product quality is sufficiently high. In Table 1 and 2 we provide some simulation results for some chosen values of the parameters subject to the restriction (19).

Table 1 shows the equilibrium choice of the product quality of the domestic monopoly when the market is protected from foreign competition, given the efficiency level of the local firm. Evidently, as the efficiency level goes up (i.e., as $\mathrm{b}$ falls), the pre-liberalization domestic product quality becomes higher and higher. The relation between $\mathrm{b}$ and $\mathrm{u}_{\mathrm{m}}$ is shown by the downward sloping convex dotted curve $u_{m} u_{m}{ }^{\prime}$ in Figure 1. Clearly, $u_{m} u_{m}{ }^{\prime}$ is defined for $b \in(0,1)$.

Then Table 2 portrays equilibrium quality choices of the local firm when it faces competition from a superior quality producing foreign firm. Given (18) and (19), Table 2 shows different values of $u$ for various values of $\mathrm{b}$ and $\mathrm{u}_{0}$. In Figure $1 u u$ ' curves show the relation between $b$ and $u$ for different values of $u_{0}$, given (19). In other words, $u u^{\prime}$ curves are defined for $b \in\left(\frac{2}{3 u_{0}}, 1\right)$. Each such curve is downward sloping and convex. This also means that, as in the case of protection, under full liberalization the efficiency of the local firm and the equilibrium product quality both move in the same direction.

Table 1. Equilibrium values of $\mu \mathrm{m}$ for different values of $b$

\begin{tabular}{cccccc}
\hline $\mathrm{b}$ & .75 & .8 & .85 & .9 & 1 \\
\hline$u_{m}$ & .88889 & .83333 & .78431 & .74074 & .66666 \\
\hline
\end{tabular}

Table 2. Equilibrium values of $\mathrm{u}$ for different values of $b$ and $u_{0}$

\begin{tabular}{cc|ccccc}
\hline \multicolumn{1}{c}{} & $b$ & .75 & .8 & .85 & .9 & 1 \\
\hline 1 & .719225 & .6168491 & .566995 & .529395 & .472056 \\
1.3 & & .83374 & .735134 & .673266 & .586490 \\
1.5 & & 1.008615 & .846652 & .766022 & .658711 \\
1.6 & & & .902232 & .811544 & .693840 \\
2 & & & 1.123280 & .98875 & .8292076 \\
3 & & & 1.6661873 & 1.4056047 & 1.144760 \\
\hline
\end{tabular}


Figure 1. Local firm efficiency and the product quality

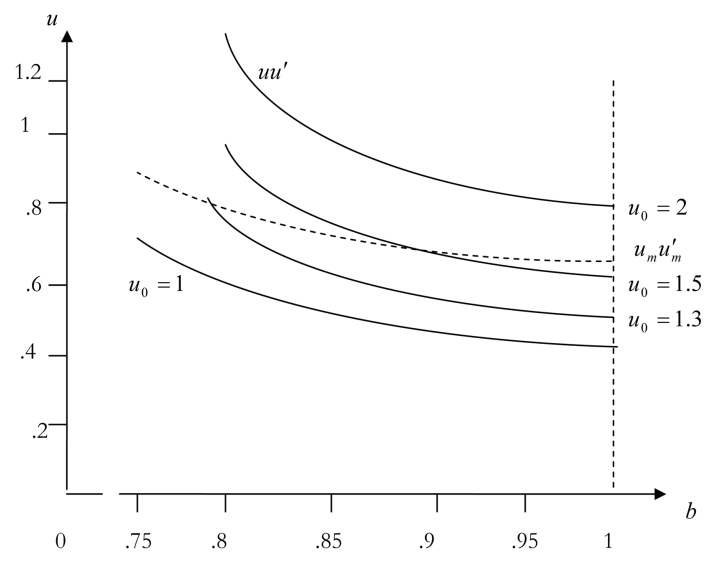

Following results can be observed from our simulation exercise.

Result 1: With respect to an increase in efficiency, the local firm's quality choice responds more under liberalization than under protection.

This follows from the fact that within the permissible range of $\mathrm{b}$, the $u u^{\prime}$ curves are steeper than $u_{m} u_{m}{ }^{\prime}$ curve, that is, $\left|\frac{\partial u}{\partial b}\right|>\left|\frac{\partial u_{m}}{\partial b}\right|$ for any given $u_{0}$. This also means that there is a single intersection between these curves for any given $u_{0}$. The economic reason is that the local firm tries to exploit its efficiency more in order to compete with the foreign firm under liberalization.

Result 2: The local firm will lower its quality after liberalization if the foreign firm enters with a quality not much higher than that of the local firm.

The result is seen in Figure 1. For example, when $u_{0}=1$, the whole $u_{m} u_{m}{ }^{\prime}$ curve is above the curve $u u^{\prime}$ whereas when $u_{0}=1.3$, one portion of the curve is below the $u_{m} u_{m}{ }^{\prime}$ curve, although we have $b<1$. This means that the local firm will lower its quality if the initial quality difference is very small. Intuition of the result is the following. After entering the local market, the foreign firm captures the upper end of the market with a slight higher quality of the product. Hence in order to compete with the foreign firm, the local firm will lower its quality in order to increase the quality difference from the foreign firm and will try to capture the lower end of the market not served previously. Here by competing both in terms of qualities and 
prices, the firm increases its profits by differentiating qualities.

Result 3: When the foreign firm enters with a relatively high quality, the optimal response of the local firm is to increase its quality.

Again this is shown in the figure. For example, when $u_{o} \geq 2$, the whole $u u^{\prime}$ curve lies above the $u_{m} u_{m}{ }^{\prime}$ curve. This means, the local firm produces a higher quality after facing competition from the foreign firm if the initial quality difference $\left(u_{o}-u_{m}\right)$ is sufficiently high. The intuition is that the local firm, being more efficient, can provide a specific quality at a lower marginal cost compared to the foreign firm. Hence at the face of competition, the local firm follows the strategy of increasing quality. So it captures some market which would otherwise go to the foreign firm.

Summarizing the above discussion we have the following proposition.

Proposition 3 : Given initially a protective regime, a shift of policy towards full liberalization will result in an improvement of the domestic quality of the product if and only if the foreign firm enters with a sufficiently higher quality of the good; the local quality will necessarily fall if the foreign product quality is sufficiently lower. If the foreign product quality is in the intermediate level, the local product quality will go up if and only if the local efficiency level is above a critical level. Formally, (i) if $u_{o}<u_{0}^{*}$, then $u<u_{m} \forall b$, (ii)) if $u_{o}>u_{0}^{* *}$, then $u>u_{m} \forall b$, and (iii) if $u_{0} \in\left[u_{0}^{*}, u_{0}^{* *}\right]$ then $\exists b_{0}\left(u_{o}\right) \mid u<,=,>u_{m} \Leftrightarrow b>,=,<b_{o}\left(u_{o}\right)$, and as $u_{o}$ increases, $b_{o}\left(u_{o}\right)$ also increases.

Case (i) and (ii) are in fact results 2 and 3 above. The intuition of case (iii) is the following. If $u_{0}$ is in the intermediate range, initial quality difference is not that much. If $b$ is below the critical efficiency level $b_{o}\left(u_{o}\right)$ i.e., if the local firm is quite efficient in R\&D activity compared to the foreign firm, then, the competitive strategy of the domestic firm is to increase the quality level and snatch a part of the market from the foreign firm; when $b$ is above the critical level, that is, the local $\mathrm{R} \& \mathrm{D}$ efficiency is not that high, the local firm will reduce its quality level to expand its market from lower end. Given the properties of $u_{m} u_{m}{ }^{\prime}$ and $u u^{\prime}$ curves, the critical $b_{0}$ increases as $u_{0}$ increases. 


\section{Conclusion}

In this paper we have studied the effect of trade liberalization on the choice of the product quality of a domestic firm. It is shown that in a protective regime the market size of the domestic monopoly is independent of its efficiency level. The implication is that the monopolist can maintain a fixed market size from the upper end of the market and can reap a higher profit by increasing efficiency and hence improving the product quality. When liberalization occurs, a foreign firm enters into the domestic market with a higher product quality and captures some market of the local firm from the upper end. Then we show that in the face of competition the local firm improves its product quality if the foreign firm enters with a substantially higher quality of goods. The local quality, however, falls if the foreign firm's product quality is below a critical level. This has policy implications. If the local government is concerned for the quality choice of the domestic firm, it must make sure that the foreign firm enters with a sufficiently higher quality good. In our structure as the efficiency of the local firm goes up, its quality choice responds more under liberalization than under protection. Hence the local government is also concerned for improving local efficiency if the country is to benefit from a policy of liberalization.

\section{Ackonwledgements}

This is a revised version of its earlier draft. Authors would like to thank an anonymous referee of this journal for comments and suggestions. They are also grateful to Dr. Sanjay Sen (Dept. of Applied Mathematics, Calcutta University) for his kind help to get the simulation results.

Received 5 November 2004, Accepted 7 December 2005 


\section{Appendix}

\section{Appendix 1}

From equation (8) we can write

$$
\frac{p_{m}}{u_{m}}=\frac{1}{2}\left(1+b \frac{u_{m}}{2}\right) \text { or }, \quad p_{m}=\frac{u_{m}}{2}\left(1+b \frac{u_{m}}{2}\right)
$$

On substitution in (9) and after simplification we shall get

$$
\left(1-\frac{b u_{m}}{2}\right)\left(\frac{1}{2}-\frac{3}{4} b u_{m}\right)=0 .
$$

Therefore, we have either $b u_{m}=2$ or $b u_{m}=2 / 3$. But when $b u_{m}=2$, the market size becomes $1-\alpha=0$, and when $b u_{m}=2 / 3$, the market size is $1-\alpha=1 / 3$. Hence the relevant solution in our case is $u_{m}=2 / 3 b$. The corresponding price and profits are $p_{m}=4 / 9 b$ and $\pi_{m}=2 / 27 b$.

\section{Appendix 2}

Given $\alpha_{1}=\frac{p_{1}-p_{2}}{u_{o}-u}$,

$$
\frac{d \alpha_{1}}{d u}=\left[\left(u_{o}-u\right) \frac{d\left(p_{1}-p_{2}\right)}{d u}+\left(p_{1}-p_{2}\right)\right]\left(u_{o}-u\right)^{2} .
$$

Then using (15), (16) and the results in Lemma 1, we have,

$$
\begin{aligned}
& \left(u_{0}-u\right) \frac{d\left(p_{1}-p_{2}\right)}{d u}+\left(p_{1}-p_{2}\right) \\
= & \left(u_{0}-u\right) \frac{1}{4 u_{0}-u}\left[-\left(2 u_{0}-u\right)-b u_{0} u-p_{1}\right]+\frac{1}{4 u_{0}-u}\left[\begin{array}{c}
\left(2 u_{0}-u\right)\left(u_{0}-u\right) \\
+\frac{u_{0}^{2}}{2}\left(2 u_{0}-u\right)-\frac{b u_{0} u^{2}}{2}
\end{array}\right] \\
= & \frac{1}{4 u_{0}-u}\left[-\left(u_{0}-u\right) b u_{0} u-p_{1}\left(u_{0}-u\right)+\frac{u_{0}^{2}}{2}\left(2 u_{0}-u\right)-\frac{b u_{0} u^{2}}{2}\right] \\
= & \frac{1}{2\left(4 u_{0}-u\right)}\left[-b u_{0} u\left(2 u_{0}-u\right)-2 p_{1}\left(u_{0}-u\right)+u_{0}^{2}\left(2 u_{0}-u\right)\right]
\end{aligned}
$$




$$
\begin{aligned}
& =\frac{1}{2\left(4 u_{0}-u\right)}\left[-b u_{0} u\left(2 u_{0}-u\right)-\frac{2 u_{0}}{4 u_{0}-u}\left\{2\left(u_{0}-u\right)+u_{0}^{2}+\frac{b u^{2}}{2}\right\}\left(u_{0}-u\right)+u_{0}^{2}\left(2 u_{0}-u\right)\right] \\
& =\frac{u_{0}}{2\left(4 u_{0}-u\right)^{2}}\left[-b u\left(2 u_{0}-u\right)\left(4 u_{0}-u\right)-2\left\{2\left(u_{0}-u\right)+u_{0}^{2}+\frac{b u^{2}}{2}\right\}\left(u_{0}-u\right)+u_{0}\left(2 u_{0}-u\right)\left(4 u_{0}-u\right)\right] \\
& =\frac{u_{0}}{2\left(4 u_{0}-u\right)^{2}}\left[-b u_{0} u\left(8 u_{0}-5 u\right)-4\left(u_{0}-u\right)^{2}+\left(6 u_{0}^{3}-4 u_{0}^{2} u+u_{0} u^{2}\right)\right] \\
& =\frac{u_{0}}{2\left(4 u_{0}-u\right)^{2}}\left[-4\left(u_{0}-u\right)^{2}+u_{0}\left\{-b u\left(8 u_{0}-5 u\right)+\left(6 u_{0}^{2}-4 u_{0} u+u^{2}\right)\right\}\right] \\
& =\frac{u_{0}}{2\left(4 u_{0}-u\right)^{2}}\left[-4\left(u_{0}-u\right)^{2}+u_{0}\left\{\begin{array}{l}
4\left(u_{0}-u\right)^{2}+2 u_{0}\left(u_{0}-b u\right)-2 b u\left(u_{0}-u\right)+ \\
\left(4 u_{0} u-3 u^{2}\right)(1-b)
\end{array}\right\}\right. \\
& =\frac{u_{0}}{2\left(4 u_{0}-u\right)^{2}}\left[4\left(u_{0}-u\right)^{2}\left(u_{0}-1\right)+u_{0}\left\{2 u_{0}\left(u_{0}-b u\right)-2 b u\left(u_{0}-u\right)\right\}+u_{0} u\left(4 u_{0}-3 u\right)(1-b)\right]
\end{aligned}
$$

For $u_{0} \geq 1$ and $b \leq 1$, this term is positive, and therefore, $\frac{d \alpha_{1}}{d u}>0$.

Now consider $\frac{d \alpha_{2}}{d u}$ where $\alpha_{2}=\frac{p_{2}}{u}$. Therefore,

$$
\frac{d \alpha_{2}}{d u}=\frac{1}{u^{2}}\left(u \frac{d p_{2}}{d u}-p_{2}\right)
$$

Now,

$$
\begin{aligned}
u \frac{d p_{2}}{d u}-p_{2} & =\frac{u}{4 u_{0}-u}\left[-u+2\left(b u_{0} u+p_{1}\right)\right]-\frac{u}{4 u_{0}-u}\left[\left(u_{0}-u\right)+\frac{u_{0}^{2}}{2}+b u_{0} u\right] \\
& =\frac{u}{4 u_{0}-u}\left[b u_{0} u-u_{0}-\frac{u_{0}^{2}}{2}+2 p_{1}\right] \\
& =\frac{u}{4 u_{0}-u}\left[b u_{0} u-u_{0}-\frac{u_{0}^{2}}{2}+p_{2}+u_{0}-u+\frac{u_{0}^{2}}{2}\right] \quad(\text { using Eq. (13(ii))) } \\
& =\frac{u}{4 u_{0}-u}\left[b u_{0} u-u+\frac{u}{4 u_{0}-u}\left(u_{0}-u+\frac{u_{0}^{2}}{2}+b u_{0} u\right)\right](\operatorname{using}(16))
\end{aligned}
$$




$$
\begin{aligned}
& =\frac{u}{\left(4 u_{0}-u\right)^{2}}\left(-3 u_{0} u+4 b u_{0}{ }^{2} u+\frac{u_{0}{ }^{2} u}{2}\right) \\
& =\frac{u_{0} u^{2}}{\left(4 u_{0}-u\right)^{2}}\left(-3+4 b u_{0}+\frac{u_{0}}{2}\right)>0 \text { for } \frac{2}{3 u_{0}}<b<1 \text { and } u_{0} \geq 1
\end{aligned}
$$

Hence $\frac{d \alpha_{2}}{d u}>0$. .

\section{Appendix 3}

From the first order condition of the first stage (Eq. (17))

$$
\begin{aligned}
& \left(\frac{\partial p_{2}}{\partial u}-b u\right)\left(\frac{p_{1}-p_{2}}{u_{0}-u}-\frac{p_{2}}{u}\right) \\
& +\left(p_{2}-\frac{b u^{2}}{2}\right)\left[\frac{p_{1}-p_{2}}{\left(u_{0}-u\right)^{2}}+\frac{1}{u_{0}-u} \frac{\partial p_{1}}{\partial u}-\frac{1}{u_{0}-u} \frac{\partial p_{2}}{\partial u}+\frac{p_{2}}{u^{2}}-\frac{1}{u} \frac{\partial p_{2}}{\partial u}\right]=0 \\
& \text { or, }\left(\frac{\partial p_{2}}{\partial u}-b u\right) \frac{u_{0}}{\left(u_{0}-u\right) u}\left(p_{2}-\frac{b u^{2}}{2}\right)+ \\
& \left(p_{2}-\frac{b u^{2}}{2}\right)\left[\frac{p_{1}-p_{2}}{\left(u_{0}-u\right)^{2}}+\frac{1}{u_{0}-u} \frac{\partial p_{1}}{\partial u}-\frac{1}{u_{0}-u} \frac{\partial p_{2}}{\partial u}+\frac{p_{2}}{u^{2}}-\frac{1}{u} \frac{\partial p_{2}}{\partial u}\right]=0 \\
& \text { [from Eq. (13)] } \\
& \text { or, } \frac{u_{0}}{\left(u_{0}-u\right) u} \frac{\partial p_{2}}{\partial u}-\frac{b u_{0}}{u_{0}-u}+\frac{p_{1}-p_{2}}{\left(u_{0}-u\right)^{2}}+\frac{1}{u_{0}-u} \frac{\partial p_{1}}{\partial u}+\frac{p_{2}}{u^{2}}-\frac{u_{0}}{\left(u_{0}-u\right) u} \frac{\partial p_{2}}{\partial u}=0 \\
& \text { or, }-b u_{0}+\frac{p_{1}-p_{2}}{u_{0}-u}+\frac{p_{2}}{u^{2}}\left(u_{0}-u\right)+\frac{\partial p_{1}}{\partial u}=0 \\
& \text { or, }-b u_{0}+\frac{p_{1}-p_{2}}{u_{0}-u}+\frac{p_{2}}{u^{2}}\left(u_{0}-u\right)+\frac{1}{4 u_{0}-u}\left(-2 u_{0}+b u_{0} u+p_{1}\right)=0 \\
& o r,-b u_{0}+\left[1-\frac{p_{1}}{u_{0}-u}+\frac{u_{0}^{2}}{2\left(u_{0}-u\right)}\right]+\frac{p_{2}}{u^{2}}\left(u_{0}-u\right) \\
& +\frac{b u_{o} u}{4 u_{0}-u}-\frac{2 u_{0}}{4 u_{0}-u}+\frac{p_{1}}{4 u_{0}-u}=0 \\
& \text { or, }-b u_{0}\left(\frac{u}{4 u_{0}-u}-1\right)+\left(1-\frac{2 u_{0}}{4 u_{0}-u}\right)+p_{1}\left(\frac{1}{4 u_{0}-u}-\frac{1}{u_{0}-u}\right)+\frac{p_{2}}{u^{2}}\left(u_{0}-u\right)+\frac{u_{0}^{2}}{2\left(u_{0}-u\right)}=0
\end{aligned}
$$




$$
\begin{aligned}
& \text { or, }-\frac{2 u_{0}\left(2 u_{0}-u\right)}{4 u_{0}-u} b+\frac{2 u_{0}-u}{4 u_{0}-u}-\frac{3 u_{0} p_{1}}{\left(4 u_{0}-u\right)\left(u_{0}-u\right)} \\
& +\left[2 p_{1}-\left(u_{0}-u\right)-\frac{u_{0}^{2}}{2}\right] \frac{u_{0}-u}{u^{2}}+\frac{u_{0}^{2}}{2\left(u_{0}-u\right)}=0 \\
& o r,-\frac{2 u_{0}\left(2 u_{0}-u\right)}{4 u_{0}-u} b+\left[\frac{2 u_{0}-u}{4 u_{0}-u}-\frac{\left(u_{0}-u\right)^{2}}{u^{2}}\right] \\
& +p_{1}\left[\frac{2\left(u_{0}-u\right)}{u^{2}}-\frac{3 u_{0}}{\left(4 u_{0}-u\right)\left(u_{0}-u\right)}\right]+\frac{u_{0}^{2}}{2}\left[\frac{1}{u_{0}-u}-\frac{u_{0}-u}{u^{2}}\right]=0 \\
& \text { or, }-\frac{2 u_{0}\left(2 u_{0}-u\right) b}{4 u_{0}-u}+\frac{u_{0}\left(9 u_{0} u-4 u_{0}^{2}-4 u^{2}\right)}{\left(4 u_{0}-u\right) u^{2}}+ \\
& +p_{1} \frac{8 u_{0}{ }^{3}-18 u_{0}{ }^{2} u+9 u_{0} u^{2}-2 u^{3}}{\left(4 u_{0}-u\right)\left(u_{0}-u\right) u^{2}}+\frac{u_{0}^{2}}{2} \frac{u_{0}\left(2 u-u_{0}\right)}{\left(u_{0}-u\right) u^{2}}=0 \\
& \text { or, }-\frac{2 u_{0}\left(2 u_{0}-u\right) b}{4 u_{0}-u}+\frac{u_{0}\left(9 u_{0} u-4 u_{0}{ }^{2}-4 u^{2}\right)}{\left(4 u_{0}-u\right) u^{2}}+\frac{u_{0}^{3}}{2 u^{2}} \frac{\left(2 u-u_{0}\right)}{\left(u_{0}-u\right)} \\
& +\frac{u_{0}\left[2\left(u_{0}-u\right)+u_{0}{ }^{2}+\frac{b u^{2}}{2}\right]}{\left(4 u_{0}-u\right)} \frac{\left[8 u_{0}{ }^{3}-18 u_{0}{ }^{2} u+9 u_{0} u^{2}-2 u^{3}\right]}{\left(4 u_{0}-u\right)\left(u_{0}-u\right) u^{2}}=0 \\
& \text { or, }-2\left(2 \mathrm{u}_{0}-u\right)\left(4 \mathrm{u}_{0}-u\right)\left(\mathrm{u}_{0}-u\right) u^{2} b+\left(9 u_{0} u-4 u_{0}^{2}-4 u^{2}\right)\left(4 \mathrm{u}_{0}-u\right)\left(\mathrm{u}_{0}-u\right) \\
& +\frac{u_{0}^{2}}{2}\left(2 \mathrm{u}-u_{0}\right)\left(4 \mathrm{u}_{0}-u\right)^{2}+\left[2\left(\mathrm{u}_{0}-u\right)+u_{0}^{2}+\frac{b u^{2}}{2}\right]\left[8 u_{0}^{3}-18 u_{0}^{2} u+9 u_{0} u^{2}-2 u^{3}\right]=0 \\
& \text { or, } \mathrm{b} u^{2}\left[-24 u_{0}^{3}+38 u_{0}^{2} u-19 u_{0} u^{2}+2 u^{3}\right]+u_{0}^{2}\left[4 u_{0}^{2} u+u_{0} u^{2}-2 u^{3}\right]+2\left(\mathrm{u}_{0}-u\right)\left(4 \mathrm{u}_{0}^{2} u-7 u_{0} u^{2}\right)=0 \\
& \text { or, }-24 b u u_{0}^{3}+38 b u_{0}^{2} u^{2}-19 b u_{0} u^{3}+2 b u^{4}+4 u_{0}^{4}+u_{0}^{3} u-2 u_{0}^{2} u^{2}+8 \mathrm{u}_{0}^{3}-22 u_{0}^{2} u+14 u_{0} u^{2}=0 \\
& \text { or, } 2 b u^{4}-19 b u_{0} u^{3}+38 b u_{0}^{2} u^{2}+14 u_{0} u^{2}-2 u_{0}^{2} u^{2} \\
& +u_{0}^{3} u-24 b u u_{0}^{3}-22 u_{0}^{2} u+8 \mathrm{u}_{0}^{3}+4 u_{0}^{4}=0 \\
& \text { or, } 2 b u^{4}-19 b u_{0} u^{3}+u_{0}\left(38 b u_{0}+14-2 u_{0}\right) u^{2} \\
& +u_{0}^{2}\left(u_{0}-24 b u_{0}-22\right) u+\left(8+4 u_{0}\right) u_{0}^{3}=0
\end{aligned}
$$

\section{References}

Bagwell, K. and R. Staiger (1989), "The role of export subsidies when product quality is unknown", Journal of International Economics 27, 69-89.

Balassa, B. (1977), "A stages approach to comparative advantage", World Bank Working Paper, No. 256.

Bhagwati, J. (1993), India in transition: Freeing the economy, Oxford University Press. Bose, P. and D.M. Kemme (2002), "Liberalization, entry and product quality in transition 
economies", Economic System 26, 353-366.

Chandra, P. and T. Sastry (1998), "Competitiveness of Indian manufacturing --- Findings of the 1997 manufacturing futures survey", Vikalpa 23, 25-36.

Chatterjee, T. and A. Raychaudhuri, (2001), "Product quality and economic liberalization: some tentative hypothesis", in R. Acharyya and B. Maitra (eds.), Effects of Globalization on Industry and Environment, Lancer's Books, New Delhi, 159-183.

Choi, J.C. and H.S. Shin (1992), "A comment on a model of vertical product differentiation", Journal of Industrial Economics 60, 229-31.

Das, S. P. and S. Donnenfeld (1987), "Trade policy and its impact on quality of imports: A welfare analysis", Journal of International Economics 23, 77-95.

Das, S. P. and S. Donnenfeld (1989), "Oligopolistic competition and international trade - quantity and quality restrictions", Journal of International Economics 27, 299-318.

Dholakia, R.H. and D. Kapur (2001), "Economic reforms and trade performance", Economic and Political Weekly 37, No 49, 4560-4566.

Donnenfeld, S., (1986), "Intra-industry trade under imperfect information about product quality", European Economic Review 30, 401-417.

Gabszewicz, J. and J.F. Thisse (1979), "Price competition, quality and income disparities", Journal of Economic Theory 20, 310-359.

Krishna, K., (1987), "Tariffs vs. quotas with endogenous quality”, Journal of International Economics 23, 96-112.

Kumar, N. (2000), "Economic reforms and their macro economic impact", Economic and Political Weekly 33, No 22, 1321-1329.

Motta, M. (1993), "Endogenous quality choice: Price vs. quantity competition", The Journal of Industrial Economics 41, 113-131.

Patibandla, M. (2002), "Product differentiation and market demand for TNCs in an emerging economy: The case of Indian durable consumer goods industries" Indian Economic Journal 49, 74-81.

Reitzes, J.D. (1992), "Quality choice, trade policy and firm incentives", International Economic Review 33, 817-835.

Rodriguez, C.A., (1979), "The quality of imports and the differential welfare effects of tariffs, quotas and quality controls on protective devices", Canadian Journal of Economics 12, 439-449.

Shaked, A. and J. Sutton (1982), "Relaxing price competition through product differentiation", Review of Economic Studies 49, 3-13.

Tanaka, Y. (1995), "Trade liberalization, product quality and consumers' welfare under monopolistic competition", Keio Economic Studies 32, 67-76.

Tirole, J. (1988), The Theory of Industrial Organization, MIT Press.

Wauthy, X. (1996), "Quality choice in the model of vertical differentiation", Journal of Industrial Economics 44, 345-353. 